\title{
Chemical Interactions in Reinforced Concrete Exposed at a Tropical Marine Environment
}

\author{
José Manuel Mendoza-Rangel, ${ }^{1}$ Pedro Castro-Borges, ${ }^{2}$ Patricia Quintana-Owen, ${ }^{2}$ \\ Mercedes Balancan-Zapata, ${ }^{2}$ and Jesús Alejandro Cabrera-Madrid ${ }^{2}$ \\ ${ }^{1}$ Facultad de Ingeniería Civil, Universidad Autónoma de Nuevo León (UANL), Avenida Universidad S/N, Ciudad Universitaria, \\ 66451 San Nicolás de los Garza, NL, Mexico \\ ${ }^{2}$ Centro de Investigación y de Estudios Avanzados del IPN, Unidad Mérida (CINVESTAV Mérida), \\ Carretera Antigua a Progreso Km. 6, 97310 Mérida, YUC, Mexico
}

Correspondence should be addressed to Pedro Castro-Borges; pcastro@mda.cinvestav.mx

Received 17 January 2015; Revised 30 May 2015; Accepted 9 June 2015

Academic Editor: Jose L. Arias

Copyright (C) 2015 José Manuel Mendoza-Rangel et al. This is an open access article distributed under the Creative Commons Attribution License, which permits unrestricted use, distribution, and reproduction in any medium, provided the original work is properly cited.

Prediction of concrete structure behavior is complicated by diverse factors, including interaction between elements and concrete compounds, chlorides diffusion through concrete, and compounds formed by corrosion of steel reinforcement. These factors were evaluated in concrete test cylinders exposed to a tropical marine environment since 1993 (during 126 months). Electrochemical, chlorides profile, scanning electron microscope, and energy-dispersive X-ray spectrophotometry analyses were done and results compared. This suite of analytical methods accurately characterized reinforced concrete condition and generated data useful in developing prediction models of corrosion in concrete structures.

\section{Introduction}

Beginning in the 1980s, service life in reinforced concrete has been classified into two stages: initiation and propagation [1]. However, during the last thirty years, new, more complex materials have been incorporated into concrete, and environmental conditions have changed. These, among other factors, have led to development of new systems dividing concrete service life into stages [2] that more specifically address the phenomena in each stage and adjust them to the changing circumstances affecting reinforced concrete.

Corrosion is more pronounced and common in marine environments and very cold places where salt is used for deicing. The main causes of steel corrosion are carbonation and chloride ions [3]. Steel reinforcement in concrete is protected against corrosion by a passive film that forms on its surface in response to the concrete's high alkalinity $(\mathrm{pH}=12.5$ to 13.5) [4]. If concrete $\mathrm{pH}$ falls below 9, or if chlorides content exceeds a certain critical value (i.e., the chlorides threshold), the steel's passive film is lost and with it any protection against corrosion. Under these conditions, corrosion products are formed with an approximate volume five times that of the reinforcing steel, producing internal tensions that cause the concrete covering to fracture and fail.

An extensive literature addresses corrosion products on steel exposed to the environment [5-14]. The main corrosion components of these products are iron oxyhydroxides $[\mathrm{FeOOH}]$, iron oxides $\left[\mathrm{Fe}_{2} \mathrm{O}_{3}\right]$, and magnetite $\left[\mathrm{Fe}_{3} \mathrm{O}_{4}\right]$. On exposed steel, the corrosion process differs from that of embedded steel reinforcement. Scanning electron microscope (SEM) studies of the paste-steel interphase in steel reinforcement have identified iron oxide and oxychloride as reaction products [15]. A base chloride $\left[3 \mathrm{Fe}(\mathrm{OH})_{2} \cdot \mathrm{FeCl}_{2}\right]$ of iron forms and then decomposes to produce akaganeite $[\beta$ $\mathrm{FeOOH}]$ and iron hydroxide [FeOOH] [16]. Final corrosion products in other studies have included magnetite $\left[\mathrm{Fe}_{3} \mathrm{O}_{4}\right]$ and akaganeite $[\beta-\mathrm{FeOOH}]$. Presence of akaganeite in the corrosion products is caused by the presence of chloride ions in the concrete [17]. 


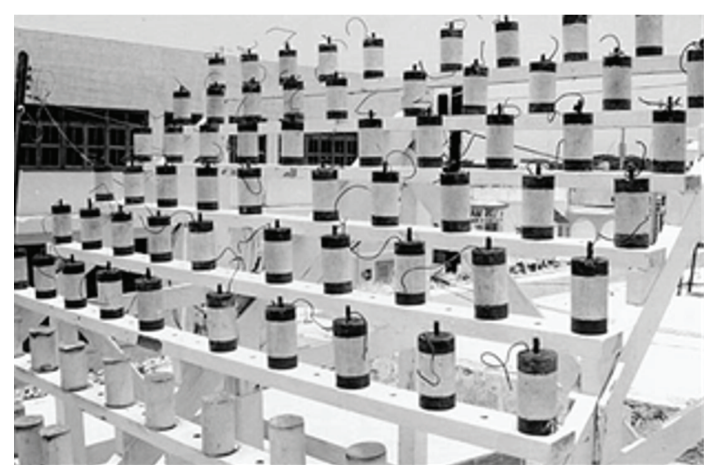

FIGURE 1: Concrete cylinders exposed to a tropical marine environment $100 \mathrm{~m}$ from the coast at Progreso, Yucatan, México $\left(21^{\circ} 18^{\prime} \mathrm{N}\right.$, $\left.89^{\circ} 39^{\prime} \mathrm{W}\right)$.

The objective of this paper was to identify the chemical elements present in the paste-steel interphase and the concrete paste itself in response to chloride ion ingress through the concrete's pore network, the interaction between them, their effect on structure service life, and the correlation between the characterization tests and electrochemical tests, using samples exposed to a tropical environment during 126 months.

\section{Experimental Methodology}

Samples for this study were taken from simple and reinforced concrete specimens exposed since 1993 in a tropical marine environment at Progreso, Yucatan, Mexico $\left(21^{\circ} 18^{\prime} \mathrm{N}\right.$, $\left.89^{\circ} 39^{\prime} \mathrm{W}\right)$; all of them were exposed for 126 months in order to obtain data since the first time of the exposure until the detection of reinforcement corrosion [18]. The cylindrical specimens were located $100 \mathrm{~m}$ from the coast, in a vertical position (Figure 1). Concrete in the test cylinders was designed to have a resistance of $30 \mathrm{MPa}$ and was made with a 0.50 water/cement $(w / c)$ ratio and a one-day set. Steel reinforcement in the test cylinders is $3 / 8^{\prime \prime}(9.5 \mathrm{~mm})$ diameter black steel rebar. The superior and inferior surfaces of each test cylinder are covered with epoxy to limit chloride action to the radial surface (Figure 2).

2.1. Chemical Tests. Before the test cylinders were placed in the marine environment and during 126 months of exposure, tests have been done for chlorides and carbonation depth. For chlorides, dust samples were taken at seven depths $(2,5,10,15,20,25$, and $30 \mathrm{~mm}$, exterior to interior) and chlorides were extracted using the acid extraction technique following established norms (ASTM C 114 and UNE 217-91). Chlorides concentration was quantified using the selective ion technique and reference electrodes (Orion, models 941700 and 9002-00, resp.). Carbonation depth was measured with the traditional technique of phenolphthalein indicator $[19,20]$. Briefly, rounds are cut from the test cylinder, dust is immediately removed from the cut surface with a brush, and phenolphthalein is applied to it. After application, appearance of a violet color indicates concrete $\mathrm{pH}$ higher than 9, and lack

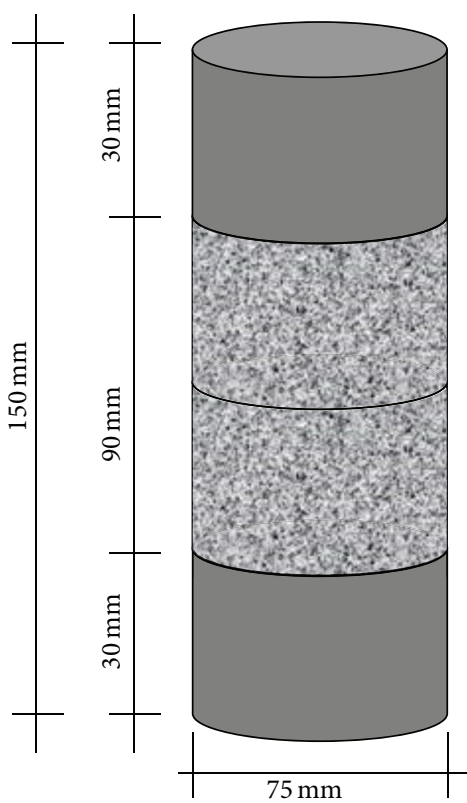

FIGURE 2: Schematic image of a concrete test cylinder: $30 \mathrm{MPa}$ compression resistance, $w / c=0.50$, one-day set.

of carbonation, while absence of any color means $\mathrm{pH}$ is lower than 9 and the concrete is carbonated.

2.2. Electrochemical Tests. In the reinforced test cylinders, steel reinforcement corrosion potential and rate were evaluated with the polarization resistance technique (Rp) following norm ASTM C-876 [21]. A potentiostat/galvanostat (PC3 ZRA) was used with the steel reinforcement as the working electrode and a titanium internal electrode, previously calibrated with a calomel-saturated electrode, as the reference electrode [22].

\subsection{Characterization Tests}

2.3.1. Corrosion Product Analysis. Steel reinforcement corrosion products were evaluated with SEM (Phillips XL30S) and EDX to identify the elements present on the steel surface and in the paste-steel interphase. The same analyses were also done of the concrete paste at different depths to identify which elements were present and their concentration. For these tests, rounds were cut from the center of the test cylinder and samples cut from these rounds at the depths mentioned above (Figure 3).

\section{Results}

The chemical and electrochemical tests of the concrete samples identified the time at which steel reinforcement depassivation, and corrosion initiation, occurred. This point also marks the end of the initiation stage and the beginning of the propagation stage.

Baseline chlorides content data at the depths mentioned above were collected before the test cylinders were exposed. 


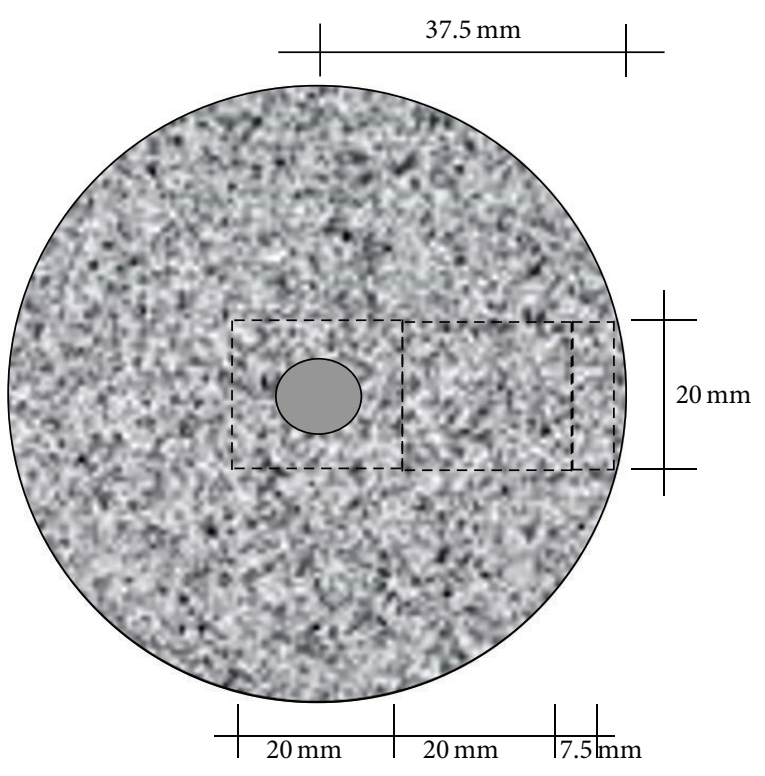

FIgure 3: Test cylinder section profile. Samples were taken at different depths for SEM and EDX analyses.

TABLE 1: Chloride concentration as a percent (\%) of concrete weight during the study period.

\begin{tabular}{ccccccc}
\hline \multirow{2}{*}{$w / c$} & Depth $(\mathrm{mm})$ & \multicolumn{5}{c}{ Months } \\
& & 0 & 24 & 45 & 78 & 126 \\
\hline \multirow{4}{*}{0.5} & 0.09 & 0.23 & 0.18 & 0.06 & 0.23 \\
& 5 & 0.07 & 0.23 & 0.19 & 0.11 & 0.22 \\
& 10 & 0.09 & 0.46 & 0.30 & 0.22 & 0.37 \\
& 15 & 0.09 & 0.44 & 0.57 & 0.19 & 0.24 \\
& 20 & 0.09 & 0.46 & 0.43 & 0.26 & 0.26 \\
& 25 & 0.08 & 0.24 & 0.45 & 0.21 & 0.62 \\
& 30 & 0.14 & 0.22 & 0.20 & 0.17 & 0.41 \\
\hline
\end{tabular}

This initial pattern was compared to the patterns measured at the same depths at different exposure times.

The free chlorides threshold required to depassivate steel reinforcement and begin its corrosion is reported to be between 0.39 and $1.16 \%$ of concrete weight [23]. Chloride concentration per concrete weight in the present data (Table 1) shows that chloride concentration increased over time and from the concrete surface towards its interior. Maximum concentration was $0.40 \%$ at 126 months and $32 \mathrm{~mm}$ depth. This is the depth of the steel surface, suggesting that the steel was depassivated. The chloride concentration profile over time (Figure 4) agrees with those reported in the literature [24].

After 126 months of exposure, carbonation had reached $20 \mathrm{~mm}$ depth. Consequently, $\mathrm{pH}$ had dropped below 9, allowing the chlorides to diffuse through the concrete paste. This is confirmed in the chloride concentration profiles.

Electrochemical tests were run to corroborate the chemical tests. Polarization resistance (Rp) was used to measure

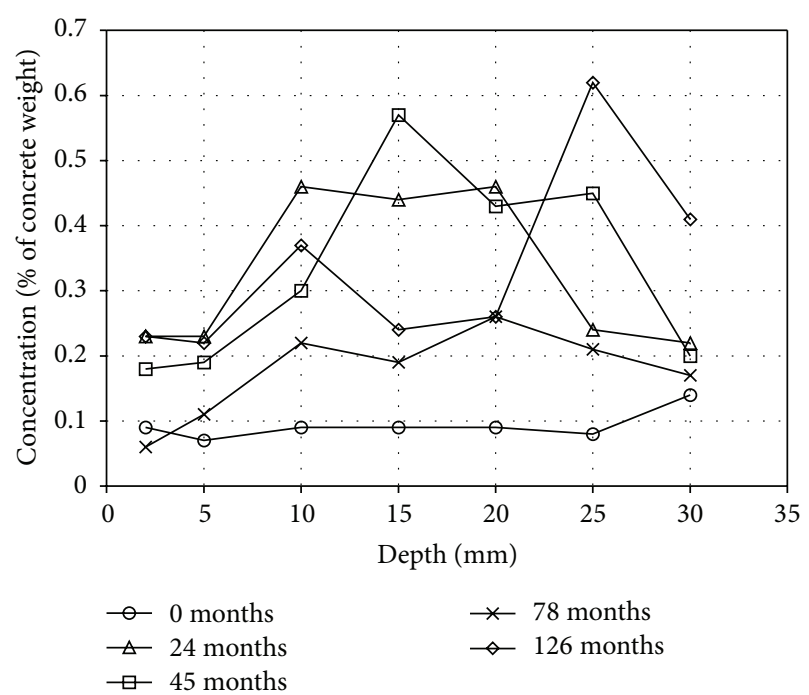

FIgURE 4: Chloride concentration at different depths over time.

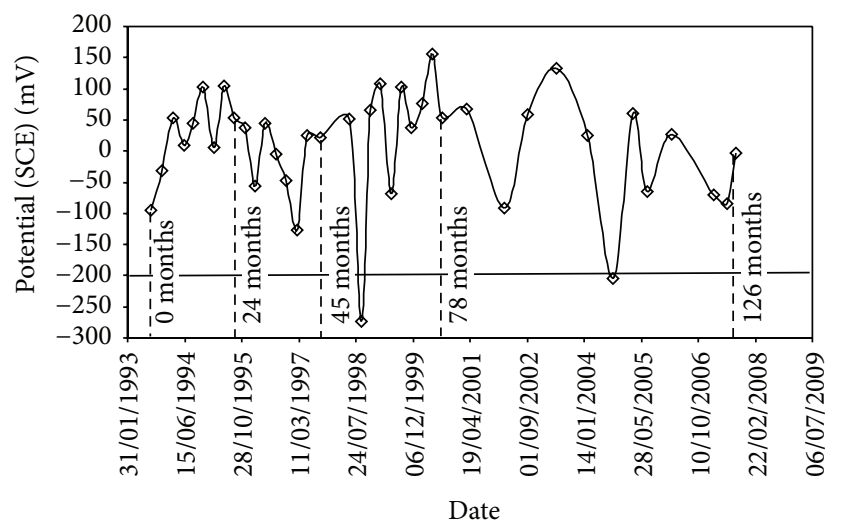

FIGURE 5: Corrosion potential over time; values below $-200 \mathrm{mV}$ indicate probable steel corrosion.

potentials and calculate corrosion rates. Using a copper/copper sulfate electrode, potentials between -200 and $-400 \mathrm{mV}$ are known to indicate possible corrosion of steel (ASTM $\mathrm{C}-876)$. The fluctuations in corrosion potential over time showed that at 60 and 126 months steel corrosion potential was between these values (Figure 5). However, they then recover and become more positive, highlighting the need to confirm these results with corrosion current measurement in $\mu \mathrm{A} / \mathrm{cm}^{2}$ to determine if corrosion was present on the steel. In this method, corrosion is known to exist on steel when corrosion current density exceeds $0.1 \mu \mathrm{A} / \mathrm{cm}^{2}[25,26]$.

Data for corrosion rate over time $\left(i_{\text {corr }}\right)$ indicated that current density surpassed $0.1 \mu \mathrm{A} / \mathrm{cm}^{2}$ beginning at 126 months (Figure 6). Corrosion had therefore begun previously and corrosion products are probably present at the interphase. At this time the test cylinders exhibited plainly visible microfractures, indicating that corrosion had begun.

The EDX analysis showed the amount of elements present and their proportions (based on peak size) at different depths 




FIGURE 6: Value for $i_{\text {corr }}$ over time; values are greater than $>0.1 \mu \mathrm{A} /$ $\mathrm{cm}^{2}$ at 126 months.

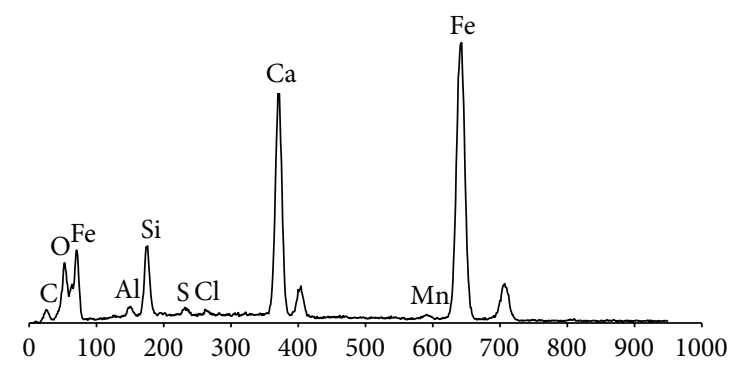

FIGURE 7: EDX analysis showing elements in the interphase and their proportions based on peak size.

TABLE 2: Amount of elements (\% of weight) as determined by SEMEDX.

\begin{tabular}{lccccccccc}
\hline $\begin{array}{l}\text { Depth } \\
(\mathrm{mm})\end{array}$ & $\mathrm{Fe}$ & $\mathrm{Ca}$ & $\mathrm{Al}$ & $\mathrm{Si}$ & $\mathrm{O}$ & $\mathrm{Mg}$ & $\mathrm{S}$ & $\mathrm{Cl}$ & $\mathrm{C}$ \\
\hline 0 & 1.9 & 51.5 & 1.7 & 7.2 & 37.5 & 0 & 0 & 0 & 0 \\
2 & 4.6 & 33.1 & 3.0 & 16.4 & 41.2 & 0.8 & 0.5 & 0 & 0 \\
5 & 2.9 & 34.6 & 2.5 & 16.2 & 40.7 & 2.0 & 0.6 & 0 & 0 \\
10 & 7.1 & 31.8 & 4.8 & 14.2 & 39.8 & 2.0 & 0 & 0 & 0 \\
15 & 5.5 & 43.0 & 2.9 & 10.0 & 35.6 & 0.7 & 1.2 & 0.7 & 0 \\
20 & 12.1 & 39.2 & 7.0 & 6.2 & 32.9 & 0.9 & 0.6 & 0.6 & 0 \\
25 & 4.8 & 35.5 & 2.8 & 9.8 & 35.3 & 0.8 & 0.6 & 0.4 & 9.6 \\
30 & 2.7 & 37.8 & 2.0 & 10.5 & 34.6 & 0.7 & 0.7 & 0.7 & 9.9 \\
\hline
\end{tabular}

$(2,5,10,15,20,25$, and $30 \mathrm{~mm})$; the concrete interphase is at $30 \mathrm{~mm}$ (Figure 7, Table 2).

\section{Discussion}

The present data indicate that during exposure chloride ions diffuse from the exterior inwards through the concrete's pore network. This produces ruptures in the passive layer, allowing steel corrosion to begin. Products such as oxychlorides and iron hydroxides form which release iron ions and other elements such as aluminum and silicon. These mix with other elements to form compounds which also diffuse through the concrete paste from the steel reinforcement towards the exterior.

It is important to mention that at $20 \mathrm{~mm}$ depth and 126 months of exposure, when signs of corrosion were visible, total chlorides concentration began to decrease while iron and aluminum concentrations at the same depth began to increase (Figure 4, Table 2). A possible explanation for these results is that as the chlorides advance through the concrete bulk they mix with other elements, such as iron and aluminum, from corrosion products. In contrast, these diffuse outwards from the center, remaining isolated or mixing little with other elements.

Silicon levels decreased with depth up to $20 \mathrm{~mm}$ and then increased (Table 2), behavior in good agreement with the carbonation observed beginning at $20 \mathrm{~mm}$ in the chemical analyses. This element forms part of the hydrated calcium silicates (HCS) in the concrete. It is therefore probably dissolving due to carbonation and then combining with portlandite $\left[\mathrm{Ca}(\mathrm{OH})_{2}\right]$ to form calcium carbonate $\left[\mathrm{CaCO}_{3}\right]$ since calcium also decreases at this point (Table 2).

Unlike silicon, chloride concentration at 126 months and $25 \mathrm{~mm}$ depth exhibited a maximum peak; indeed it was the highest concentration in a test cylinder (Figure 4, Table 2). At the same depth, elements such as iron and aluminum decreased. Silicon concentrations also increased, which agrees with a lack of carbonation at this depth.

The data produced to date with this experiment suggest strong correlations between chemical and electrochemical phenomena and the behavior of elements and compounds in the reinforced concrete. Further research will be needed to corroborate these findings over longer time periods and in different qualities of concrete. The results also confirm that characterization tests are vital to determining concrete durability and that improvements can be made to an overall service life prediction model based solely on chloride diffusion. Stage-based models can help to make predictions more accurate.

\section{Conclusions}

Any conclusions drawn from the present study apply largely to the study conditions and can only be carefully extrapolated to broader contexts. Tools such as SEM and EDX clearly provide valuable data for comparing chemical and electrochemical findings.

The chloride ions diffusion from the exterior inwards through the concrete's pore network produces ruptures in the passive layer, allowing steel corrosion to begin. This phenomenon can be detected through the joint analyses of chemical, electrochemical, and characterization tests. This in turn creates greater accuracy in service life prediction models, particularly those divided into various stages.

Collecting data from test cylinders exposed for long periods in marine environments helps to establish trustworthy durability parameters that can be compared to real structures under service conditions, with the additional consideration of factors not included in the present study, such as load conditions. 


\section{Conflict of Interests}

The authors declare that there is no conflict of interests regarding the publication of this paper.

\section{Acknowledgments}

This work received partial support from the CONACYT (Project no. Ciencia Básica 155363) and from the PROMEP (Project no. 103.5/11/4330), PAICYT (Project no. IT520-10), and CONACYT (Project nos. Ciencia Básica 57420 and CIAM 54826).

\section{References}

[1] K. Tuutti, "Corrosion of steel in concrete," Research Report 4, CIB, Stockholm, Sweden, 1982.

[2] P. Castro-Borges and P. Helene, "Service life of reinforced concrete structures. New approach," ECS Transactions, vol. 3, no. 13, pp. 9-14, 2007.

[3] G. S. Duffó, W. Morris, I. Raspini, and C. Saragovi, "A study of steel rebars embedded in concrete during 65 years," Corrosion Science, vol. 46, no. 9, pp. 2143-2157, 2004.

[4] C. P. Page and K. W. J. Treadaway, "Aspects of the electrochemistry of steel in concrete," Nature, vol. 297, no. 5862, pp. 109-115, 1982.

[5] H. Leidheiser Jr. and S. Musić, "The atmospheric corrosion of iron as studied by Mössbauer spectroscopy," Corrosion Science, vol. 22, no. 12, pp. 1089-1096, 1982.

[6] H. Leidheiser Jr. and I. Czakó-Nagy, "A Mössbauer spectroscopic study of rust formed during simulated atmospheric corrosion," Corrosion Science, vol. 24, no. 7, pp. 569-577, 1984.

[7] J. T. Keiser, C. W. Brown, and R. H. Heidersbach, "Characterization of the passive film formed on weathering steels," Corrosion Science, vol. 23, no. 3, pp. 251-259, 1983.

[8] J. B. Johnson, P. Elliott, M. A. Winterbottom, and G. C. Wood, "Short-term atmospheric corrosion of mild steel at two weather and pollution monitored sites," Corrosion Science, vol. 17, no. 8, pp. 691-700, 1977.

[9] M. Stratmann and K. Hoffmann, "In situ Mößbauer spectroscopic study of reactions within rust layers," Corrosion Science, vol. 29, no. 11-12, pp. 1329-1352, 1989.

[10] J. Avila-Mendoza, J. M. Flores, and U. C. Castillo, "Effect of superficial oxides on corrosion of steel reinforcement embedded in concrete," Corrosion, vol. 50, no. 11, pp. 879-885, 1994.

[11] H. E. Townsend, T. C. Simpson, and G. L. Johnson, "Structure of rust on weathering steel in rural and industrial environments," Corrosion, vol. 50, no. 7, pp. 546-554, 1994.

[12] A. V. R. Kumar and R. Balasubramaniam, "Corrosion product analysis of corrosion resistant ancient indian iron," Corrosion Science, vol. 40, no. 7, pp. 1169-1178, 1998.

[13] D. C. Cook, S. J. Oh, R. Balasubramanian, and M. Yamashita, "The role of goethite in the formation of the protective corrosion layer on steels," Hyperfine Interactions, vol. 122, no. 1-2, pp. 5970, 1999.

[14] T. Kamimura, T. Doi, T. Tazaki, K. Kuzushita, S. Morimoto, and S. Nasu, "Investigation of rust formed in steels exposed in an industrial environment," in Proceedings of the 2nd International Conference on Environment Sensitive Cracking and Corrosion Damage, pp. 190-196, Hiroshima, Japan, 2001.
[15] D. A. Koleva, J. Hu, A. L. A. Fraaij, K. van Breugel, and J. H. W. de Wit, "Microstructural analysis of plain and reinforced mortars under chloride-induced deterioration," Cement and Concrete Research, vol. 37, no. 4, pp. 604-617, 2007.

[16] V. S. Ramachandran, Concrete Science, chapter 7, Noyes/William Andrew, Norwich, UK, 2001.

[17] B. Kounde, A. Raharinaivo, A. A. Olowe, D. Rezel, P. Bauer, and J. M. R. Génin, "Mössbauer characterization of the corrossion products of steels in civil works: suspension bridge and reinforced concrete," Hyperfine Interactions, vol. 46, no. 1-4, pp. 421428, 1989.

[18] P. C. Borges, Difussion and corrosion by chloride ions in reinforced concrete [Ph.D. thesis], UNAM, 1995, (Spanish).

[19] C.-F. Chang and J.-W. Chen, "The experimental investigation of concrete carbonation depth," Cement and Concrete Research, vol. 36, no. 9, pp. 1760-1767, 2006.

[20] Y. Lo and H. M. Lee, "Curing effects on carbonation of concrete using a phenolphthalein indicator and Fourier-transform infrared spectroscopy," Building and Environment, vol. 37, no. 5, pp. 507-514, 2002.

[21] J. A. González, C. Andrade, C. Alonso, and S. Feliu, "Chloride threshold values to depassivate reinforcing bars embedded in a standardized OPC mortar," Cement and Concrete Research, vol. 25, no. 2, pp. 257-264, 1995.

[22] P. Castro, A. A. Sagüés, E. I. Moreno, L. Maldonado, and J. Genescá, "Characterization of activated titanium solid reference electrodes for corrosion testing of steel in concrete," Corrosion, vol. 52, no. 8, pp. 609-617, 1996.

[23] C. Alonso, C. Andrade, M. Castellote, and P. Castro, "Chloride threshold values to depassivate reinforcing bars embedded in a standardized OPC mortar," Cement and Concrete Research, vol. 30, no. 7, pp. 1047-1055, 2000.

[24] P. Castro, O. T. De Rincón, and E. J. Pazini, "Interpretation of chloride profiles from concrete exposed to tropical marine environments," Cement and Concrete Research, vol. 31, no. 4, pp. 529-537, 2001.

[25] J. A. González, S. Algaba, and C. Andrade, "Corrosion of reinforcing bars in carbonated concrete," British Corrosion Journal, vol. 15, no. 3, pp. 135-139, 1980.

[26] J. A. González, C. Andrade, C. Alonso, and S. Feliu, "Comparison of rates of general corrosion and maximum pitting penetration on concrete embedded steel reinforcement," Cement and Concrete Research, vol. 25, no. 2, pp. 257-264, 1995. 

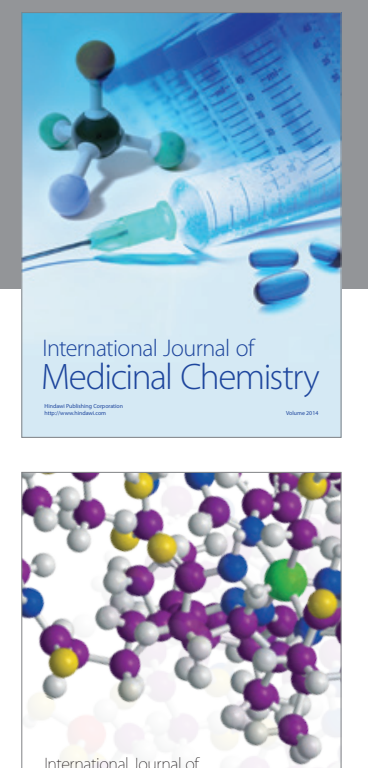

\section{Carbohydrate} Chemistry

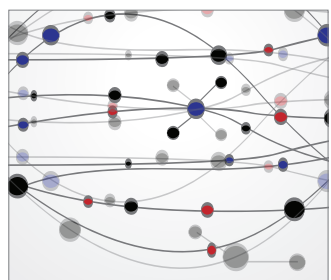

The Scientific World Journal

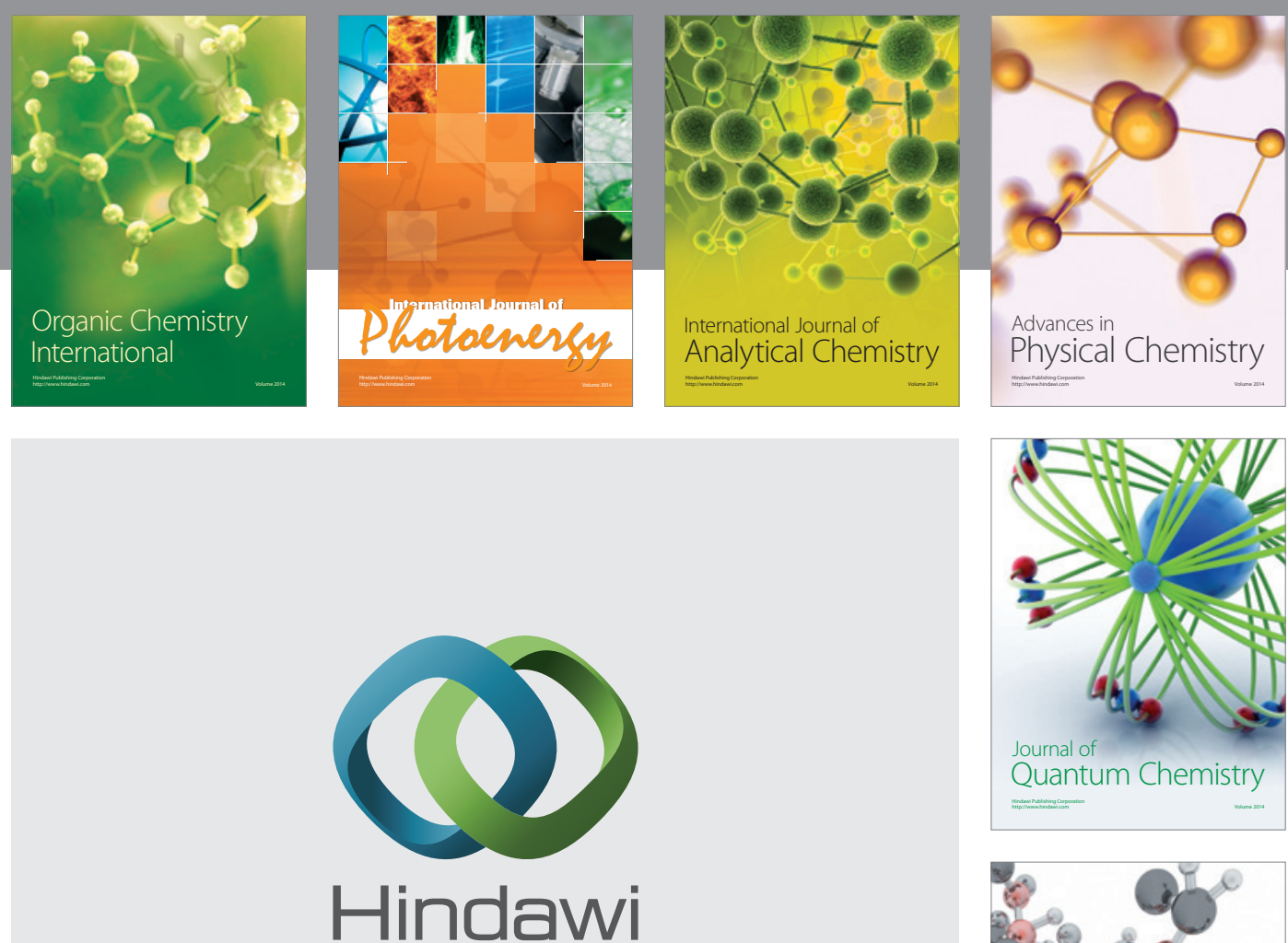

Submit your manuscripts at

http://www.hindawi.com

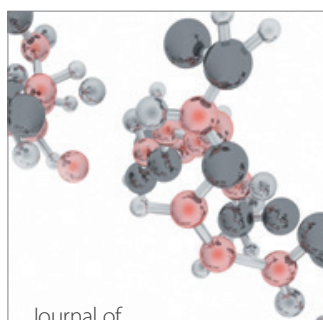

Analytical Methods

in Chemistry

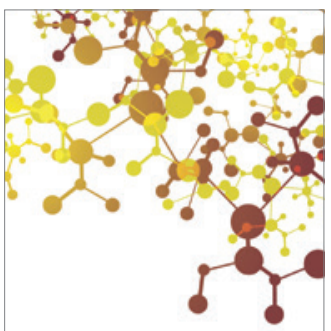

Journal of

Applied Chemistry

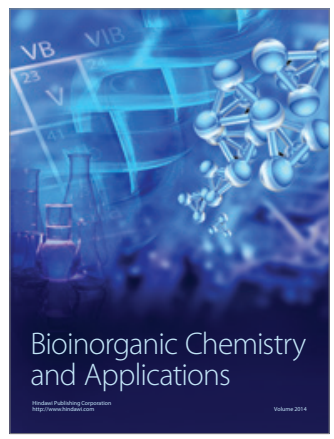

Inorganic Chemistry
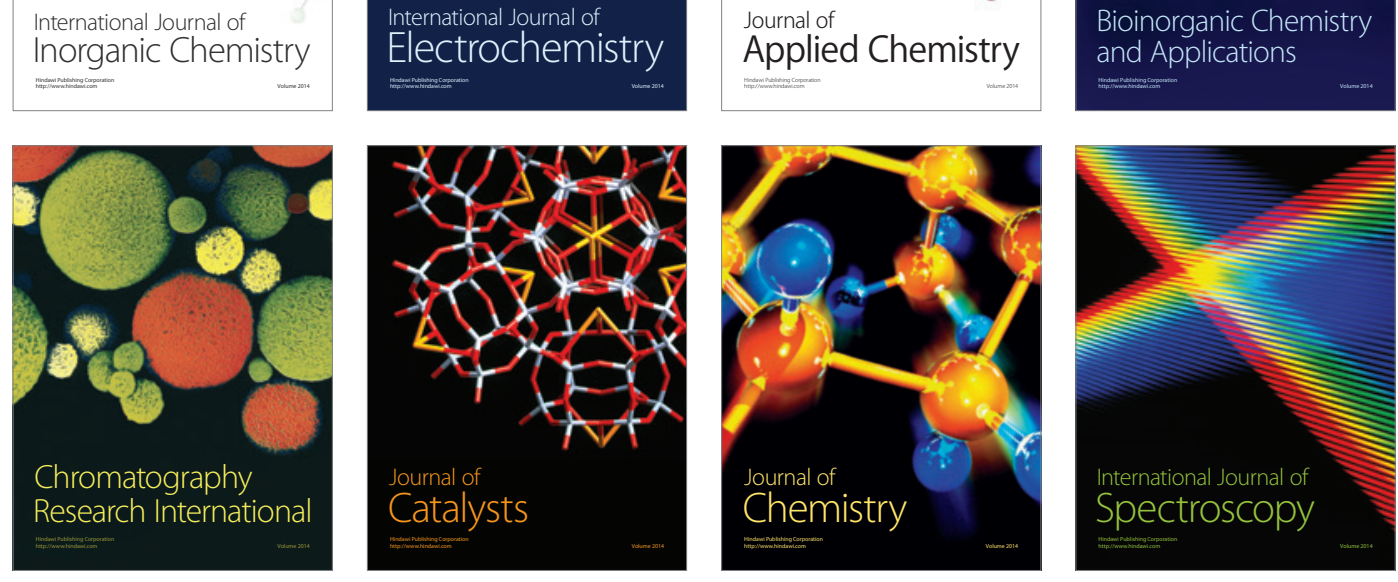